\title{
The Role of Business Analytics in Transforming Management Accounting Information into Cost Performance
}

\author{
Metin UYAR ${ }^{1}$
}

\begin{abstract}
The effects of e-commerce and big data on accounting and cost management should be evaluated comprehensively from various aspects. Increasing internet-based applications deeply affect both accounting and cost management. The effect of three basic variables is emphasized in the study. First, the relationship between business analytics and management accounting, and cost performance was evaluated. Business analytics can play an important role in the effectiveness of management accounting. The findings of the study show that descriptive and predictive analytics have positive effects on the planning, control, and cost management. The productivity increase seen in the planning and control functions of management accounting improves the cost performance in favor of the company. Managerial and practical evaluations have been made in the context of the inferences obtained from the research.
\end{abstract}

Keywords: Business analytics, management accounting, big data, cost performance, performance management, information technology.

JEL CODES: M41

\section{Introduction}

The fact that the information becomes increasingly digitized to enable the combination of conventional company data with digital data, and expansion of the data ecosystem. The changing data structure from the traditional toward digitized provides radical developments in business analytics and makes it a key to the management accounting as well as the organization performance. Big data utilization and technology contribute to a competitive advantage (Granlund, 2011; Haas and Pentland, 2014). Business analytics paves the way for management accounting applications to take advantage of both internal and external resources by expanding the data ecosystem. Analytics also allows businesses to access more data and details. Increased quality of information supports both quantitative and qualitative performance to reach the targeted level. Analytics becomes a component of organizational processes as important optimization techniques and tools used to solve problems (Zikopoulos et al., 2012;
Vidgen et al., 2017). Cost performance, which is an indicator of organizational performance, can be positively affected by the interaction between the management accounting system and business analytics.

Business analytics methods to be integrated into the management accounting system improve cost performance by strengthening various aspects of information. On the other hand, studies show that this change is not adequately reflected in management accounting (Scapens and Jazayeri, 2003). Business analytics methods and tools, including descriptive, predictive, and prescriptive features, have a positive impact on management accounting knowledge and cost performance. Technological facilities and sophisticated tools should be used more to obtain information more closely related to managerial processes (Appelbaum et al., 2017. Using business analytics allows businesses to make predictive, descriptive, and prescriptive inferences by obtaining data from various sources.

${ }^{1}$ Assoc. Prof. (Ph.D.), Business Administration, Faculty of Economics Administrative and Social Sciences, İstanbul Gelisim University, İstanbul-Turkey, meuyar@gelisim.edu.tr 
Prior studies have examined association between accounting system and business analytics (Nielsen, 2015; Silvi et al., 2010). Few studies studied the associations between the accounting system, cost performan$\mathrm{ce}$, and business analytics. The potential contributions are as follows: It is pioneering research that examines associations between accounting, cost performance, and business analytics in a holistic view by answering the questions such as "can organizations having similar management accounting systems gain more advantage using business analytics techniques?, May cost performance be developed by business analytics improving the effectiveness of managerial accounting?", "How does business analytics affect the functions of management accounting?". Secondly, an accounting-oriented multidimensional scale was developed to assess business analytics through the concepts of descriptive, predictive, and descriptive business analytics. Third, the study reveals whether management accounting plays a mediator role between cost performance and business analytics. In the second part of the study, the conceptual framework is explained. This section also includes hypotheses and the research model. The third part shows the methodology and research findings. In the last part, evaluations, discussions, and suggestions are given in line with the findings.

\section{Literature Review and Hypotheses Development}

\subsection{The Business Analytics and New Data Ecosystem}

Organizations need more sophisticated data due to uncertainty and fluctuations in business life. Virtual world and real-life provide more data called "big data" for businesses. Conventional data replaces with digitized data. This transformation expands the data ecosystem like never, bringing both advantages and challenges (Shmueli and Koppius, 2011). Consequently, business analytics are gradually increasing their impact. Business analytics refers to techniques, approaches, applications, and orientations that include data, information-communication technologies, visualization tools, statistical analysis, mathematical and quantitative models in business life to make evaluations and make rational decisions.

Business analytics helps test and understand causal phenomena in business life using mathematical and statistical methods (Davenport and Harris, 2007; Klatt et al., 2011). Research confirms that business analytics is becoming increasingly important both for present and future organizational activities (Gartner, 2012; Troilo et al., 2016; Aydıner et al., 2019). Business analytics may enhance the effective use of organizational resources.

Holsapple et al. (2014) state that business analytics applications consist of three orientations that are descriptive, predictive, and prescriptive. Orientation describes the function and content of analytics. Descriptive analytics provides an analytical summary of business activities and events and, includes basic and advanced statistical analyses, qualitative and quantitative ratios, dashboards and visual tools, and are frequently used in business (IBM, 2013; Dilla et al., 2010). Descriptive analytics describes the financial and non-financial results of the business following its interaction with the environment through statistical and other tools. It includes all kinds of data sources in the analysis rather than financial statement data. In this way, business analytics changes the traditional data-oriented view of management accounting. Predictive analytics is the next step in obtaining information from descriptive analytics. It provides forecasting about what might be (IBM, 2013). Predictive analytics is performed with probability and forecasting models, statistical advanced analyses and scoring tools. Forecasting and probability models use historical data collected over time to understand possible future events. Descriptive analytics is strongly related to the use of predictive analytics. Prescriptive analytics focuses on the question of what should be done based on data provided by the descriptive and predictive outcomes (Holsapple et al., 2014). With this feature, prescriptive analytics can be considered as an optimization technique. Prescriptive analytics take into the data of descriptive and predictive analytics to the next level by revealing possible solutions. Organizations may achieve their objectives owing to prescriptive analytics that generates solutions by processing qualitative and quantitative data obtained from various information sources (Basu, 2013).

\subsection{The Business Analytics and Management Accounting}

Management accounting has three basic roles: control and planning, performance measurement, and cost management (Cokins, 2013). Business analytics can contribute to each function of management accounting. Accountants can use the data provided by business analytics at every stage of their business. The budget to be prepared using the data obtained from social media can be given as an example. In this way, risk analysis can be done to prevent the allocation of resources to wrong market segments. In addition, social 
media and industry reports can help managements redesign their business processes.

Analytics tools positively affect the performance evaluation, as they include sophisticated tools such as text mining, machine learning, and data mining (Nielsen, 2015; Warren et al., 2015). Accounting data quality enhances owing to business analytics. High-data quality is one of the prerequisites of business management (Chae et al., 2014; Redman, 2013). Business analytics helps to provide quality data for data users to make valuable analyzes and predictions. In this context, business analytics utilization improves the performance of the accounting system. The management accounting system performs basic functions such as strategic cost management, operational control, and performance measurement, budgeting, and reporting (Brands, 2015). Information produced through reporting should be predictive rather than historical based (Cokins, 2013). Therefore, the need for predictive accounting information and financial statements is increasing rather than historical accounting information and financial statements. It will be useful to integrate business analytics methods into accounting and corporate resource planning systems to realize this change and transformation by enterprises.

Descriptive analytics improves the cost management function of accounting as it helps to summarize and explain an entity's cost structure. Sivarajah et al. (2017) addressed those analytics are applied in conjunction with dashboards, scorecards, data visualization to monitor operational processes. Predictive and descriptive analytics such as machine learning, statistical analysis, mathematical modeling, trend analysis, a regression equation can be used in performance measurement and evaluation studies. Prescriptive analytics can improve the efficiency of both cost management and planning by contributing to the determination of optimal solutions. The planning and control function can be performed more efficiently through scenarios provided by risk analytics and prescriptive analytics.

Due to predictive, prescriptive, and descriptive analytics, management accounting can provide more optimal solutions in solving business problems. In this way, instead of relying on internal data, management accounting can perform more comprehensive analyses that consider external data. Relatively difficult processes, such as cost reduction, supplier selection, measurement of company reputation, quality, and pricing in material management, can be made by management accounting easier and more feasible owing to business analytics tools. Increased effectiveness of management accounting allows the firm to focus more on cost performance. In this context, business analytics positively affects management accounting and cost performance.

Prescriptive analytics utilization not only reduces costs, but also increases the effectiveness of accounting in understanding new markets, developing new products, and determining customer preferences. Data from social media facilitates changes in consumer preferences and understanding of trends by the business. Thus, management accounting can perform more realistic analyzes both in planning activities and in cost management.

Business analytics improves the planning and control effectiveness of management accounting by providing the data needed to help businesses get to know their customers better. For example, indicators such as customer satisfaction, the return rate of products, customer complaints can be easily monitored through analytics. The analytics also enable the accounting unit to compile customer ratings from various websites or forums. The effect of this change is seen in the creation of a social media analysis team for many companies. Analytical techniques, such as text mining, enable the accountant to perform budgeting and control more effectively by identifying the frequency of company brands taking part in customer conversations (such as Facebook, Instagram, Pinterest). Analysis on Facebook, Twitter, Instagram statistics can be reflected in the management accounting studies through business analytics tools. Business analytics contribute to management accounting for evaluating the internal processes of the business.

The use of descriptive analytics enables internal processes to be summarized for managers. Summarizing and aggregating data increases the success of planning and control functions (Jans et al., 2013; Sun et al., 2017). The evaluation of internal performance and development of forecasting models can be easier with predictive analytics utilization. Management accounting controls the success levels of internal processes and objectives using transaction mining. Descriptive analytics contribute to the quality of control by providing descriptors such as mean, median and standard deviation for managerial processes. Prescriptive and predictive methods support management in developing employee skills, improving product quality. An example is when the accountant chooses a raw material supplier using an optimization model that 
increases revenue by reducing costs in the production process (Taleizadeh et al., 2015). Business analytics has a vital position in creating value and using resources effectively (Hindle and Vidgen, 2018). In this context, it is important to analyze the relationship between the accounting system and the use of business analytics. The hypotheses developed according to the evaluations are as follows:

$\mathrm{H} 1 \mathrm{a}$ :The more intensive use of descriptive business analytics by the enterprise positively affects the cost management dimension of management accounting.

$\mathrm{H} 1 \mathrm{~b}$ : The more intensive use of predictive business analytics by the enterprise positively affects cost management function.

$\mathrm{H} 1 \mathrm{c}$ :The more intensive use of prescriptive business analytics by the enterprise is positively associated with cost management.

H1d: Descriptive business analytics positively affects the planning and control function of management accounting in the enterprises.

H1e: Predictive business analytics positively affects the planning and control activities in the enterprises.

H1f: Prescriptive business analytics positively affects the planning and control activities in the enterprises.

H1g: Descriptive business analytics positively affects performance measurement and evaluation in enterprises.

$\mathrm{H} 1 \mathrm{~h}$ : The predictive business analytics is positively associated with the performance measurement and evaluation in the enterprises.

$\mathrm{H} 1 \mathrm{i}$ : The prescriptive business analytics affects the performance measurement and evaluation activities in the enterprises in the positive direction

\subsection{Cost Performance, Business Analytics, and Management Accounting}

In response to competition, businesses gradually increase competition in each component of products and services (Stenzel and Stenzel, 2004). Cost and quality are important factors that enable businesses to survive the competition. Business analytics utilization helps improve product quality and business processes. Understanding business analytics and big data are important because of their impact on efficient use of resources and performance improvement (Pape, 2016).

Big data and business analytics can be used in decision-making and strategy development processes
(Davenport, 2006). The analytics utilization makes it possible to compile, process, and analyze data provided by various informational sources. Descriptive, predictive, and prescriptive analytics make it easier to define cost behavior in businesses as direct-indirect, fixed or variable. Descriptive and predictive analytics enhance the firm's ability to analyze each cost component. Wong et al., (2011) state that the analytics utilization has a significant impact on cost reduction.

Business analytics are also used in performance management. Analytics make a positive contribution to reducing costs. The use of business analytics increases efficiency and helps to make decisions that will reduce costs (Hedgebeth, 2007). Previous research displays that business analytics can make a significant contribution to product development and management (Cooper and Slagmulder, 2004). Analytics may enhance the efficiency of supply chain and operational costs (Maiga et al., 2015; Anderson and Dekker, 2009). Business analytics also improve organizational performance (Maiga and Jacobs, 2003; Krishnamoorthi and Mathew, 2018).

The use of business analytics supports knowledge sharing and creativity in businesses (Larson and Chang, 2016). In this respect, business analytics support evidence-based problem-solving techniques. Therefore, cost performance is positively affected by the evidence-based problem-solving approach of business analytics. Management accounting, which is an information system, has a positive effect on the production capability of the enterprise by affecting the sharing of information (Esfahbodi et al., 2016). Data analysis has an important role in decision-making in terms of costing processes (Cadez and Guilding, 2008). However, the cost management dimension of management accounting makes it possible to evaluate the weak and strong aspects of cost performance. Through management accounting applications such as performance measurement and planning, it is possible for the business to both evaluate and make its cost success sustainable. Hypotheses are as follows:

$\mathrm{H} 2 \mathrm{a}$ : The descriptive business analytics positively affects the cost performance.

$\mathrm{H} 2 \mathrm{~b}$ : Predictive business analytics positively affects cost performance.

$\mathrm{H} 2 \mathrm{c}$ : The prescriptive business analytics is positively associated with the cost performance.

H3a: The cost management dimension of the management accounting positively affects the cost performance in the enterprises. 
$\mathrm{H} 3 \mathrm{~b}$ : The planning and control dimension of management accounting positively affects the cost performance in the enterprises.

H3c:The performance measurement and evaluation practices in management accounting positively affect the cost performance of the enterprises.

H4: The business analytics and management accounting affect the cost performance of enterprises positively.

$\mathrm{H} 5$ : There is a significant indirect relationship between business analytics to cost performance using management accounting system.

\section{Research Method}

\subsection{Sampling and Data Collection Process}

The study is based on a questionnaire that was administered to managers and employees of the accounting department of companies which operating in Turkey. As a prerequisite, large-scale enterprises with more than 250 employees were accepted as the population. According to the official data published by the Turkish Statistical Institute, as of the end of 2019, the number of micros, small and medium-sized enterprises is $3,221,000$, which is $99.8 \%$ of the enterprises operating in Turkey. The share of large-scale enterprises is $0.2 \%$ (https://data.tuik.gov.tr/Bulten/Index?p=Kucuk-ve-Orta-Buyuklukteki-Girisim-Istatistikleri-2019-37548). In this context, the number of large-scale enterprises that constitute the population of the research is 6,455 . The contact and corporate information of the respondents in the sample were obtained from the publicly available data in the member lists of the chambers of industry and commerce. Firms were selected using the random sampling method. Random sampling is a method in which all the units in the population have an equal and independent chance of being selected for sampling. Because of this feature, the results obtained from the random sampling can be generalized to the population (Baştürk and Taştepe, 2013). The sample was selected from manufacturing, service and retail enterprises to allow cross-sector comparison. However, no distinction has been made between sub-sectors or business codes. 50 of the questionnaires were delivered to the participants through workplace visits (face-to-face). An E-mail that includes a hyperlink to the internet site where respondents could complete the questionnaire anonymously was sent to 2750 companies (online). The responses of 185 participants were determined to be proper for data analysis. We examined the adequacy of the sample size, since the sample size was 185 , althou$\mathrm{gh}$ the questionnaire form was delivered online and face-to-face to a total of 2800 respondents. We followed Daniel \& Cross (2018), and Wonnacott \& Wonnacott (1990) to determine the adequacy of sample size. We determined the sample size is adequate with a confidence level of $95 \%$ and a margin of error of $7.2 \%$. The sample size and the margin of error were determined as follows,

$$
\begin{aligned}
& n=\frac{z^{2} \rho q}{e^{2}} \\
& e=z \sqrt{\frac{p(1-P)}{n}}
\end{aligned}
$$

Where,

$n$ is the estimated sample size.

$z$ is the value to chosen alpha level for .05 this is 1.96 $p$ is the estimated proportion of the population. This is 0.5 generally

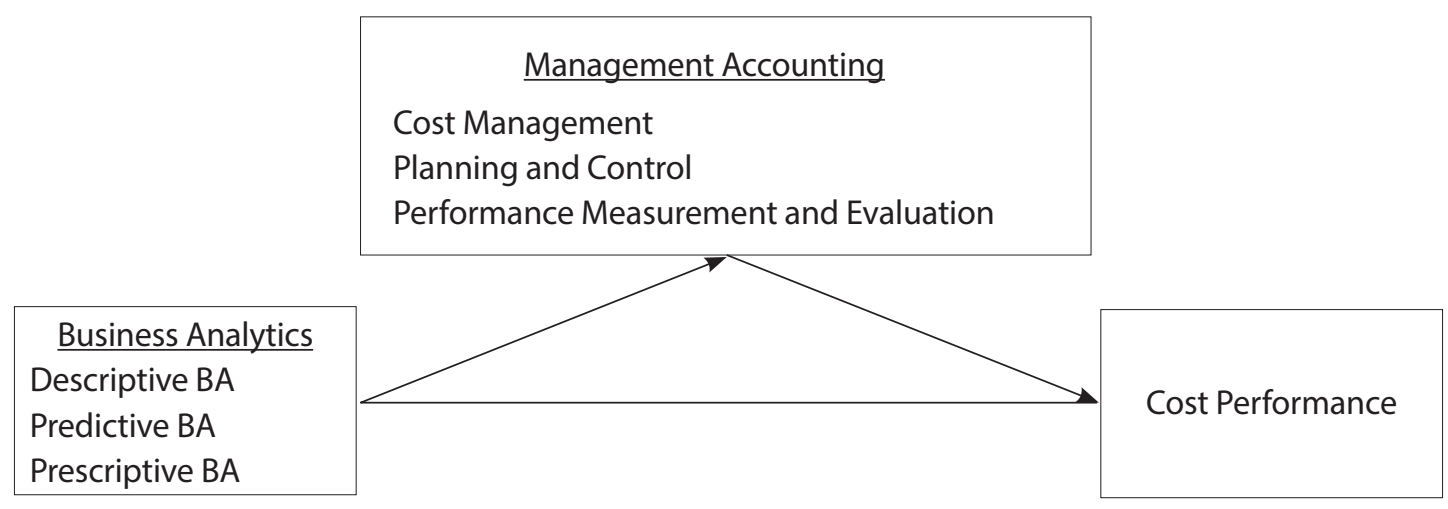

Figure 1: Research Model 
$q$ is $1-p$

$e$ is the margin of error.

Table 1 shows the sample characteristics.

Table 1: Sample Demographics

\begin{tabular}{|l|l|l|}
\hline Category & $\begin{array}{l}\text { Frequency } \\
(\mathrm{N}=37)\end{array}$ & Percentage \\
\hline $\begin{array}{l}\text { Gender } \\
\text { Female }\end{array}$ & 85 & 45.9 \\
Male & 100 & 54.1 \\
\hline Age & & \\
\hline Under 28 & 57 & 30.8 \\
Between 28-40 & 93 & 50.2 \\
Over 40 & 35 & 19.0 \\
\hline Experience & & \\
\hline 1-5 Years & 50 & 27.0 \\
6-10Years & 90 & 48.6 \\
11 Years and Above & 45 & 24.4 \\
\hline Job Title & & \\
\hline Manager & 42 & 22.7 \\
Senior Accountant & 143 & 77.3 \\
\hline Industry & 75 & 40.5 \\
\hline Retail & 60 & 32.4 \\
Manufacturing & 50 & 27.1 \\
\hline Service & 130 & 70.3 \\
\hline Organization Size (Number of & & 23.2 \\
\hline Employees) & 43 & 6.5 \\
\hline 250-1000 & 12 & \\
1001-3000 & & \\
3001 and Above & & \\
\hline
\end{tabular}

About $40 \%$ of the firms are retail, $32 \%$ are manufacturing, and $27 \%$ are from the service sector. In terms of the size of the firms, it is understood that $70 \%$ of them have 250-1000 employees. The proportion of female and male participants shows closeness.

\subsection{Pre-Testing and Measurement Design}

At this stage, the questionnaire form was delivered to 24 participants working in 20 firms by face-to-face interview method. The criteria of the face and content validity of the questionnaire were determined. Items difficult to understand are eliminated at this stage. In addition, the recommendations of the participants for the development of the questionnaire were also taken into consideration. In the design of measuring instruments, a field-specific structure was preferred considering previous research (Hindle \& Vidgen, 2018). Questions on business analytics, cost performance, and management accounting are in 5-point Likert form.

\subsubsection{The Accounting Focused Business Analytics Orientation}

It was assumed that the responders had knowledge about prescriptive, predictive, and descriptive analytics. The measurement tool was developed based on previous studies that have high reliability and validity scores. The scale includes the sub-scales relevant to business analytics. The descriptive business analytics scale includes 4 items in the total. The predictive analytics scale consists of 5 items. The prescriptive business analytics scale involves 4 items. The questions are used to the business analytics usefulness scale as follows,

Q1: In our company, ratio analysis, clustering models, process mining, Spearman rank correlations are used effectively. (Descriptive)

Q2: We frequently use descriptive statistics such as arithmetic mean, standard deviation, median about our accounting activities. (Descriptive)

Q3: Statistical descriptors and ratio analysis are used in the control activities of our business. (Descriptive)

Q4: Decision-making process in our enterprise is conducted comparing the data obtained from internal sources with the data obtained from the external sources. (Descriptive)

Q5: Artificial Neural networks, probability theory models, operations research, support vector machines are used frequently by our company. (Predictive)

Q6: Expert systems and decision tree methods are included in business processes by our company. (Predictive)

Q7: In planning activities, analytical hierarchy processes method is used effectively. (Predictive)

Q8: Predictive analysis and techniques are important for the management of our processing. (Predictive)

Q9: Predictive analysis and techniques provide benefits for cost control and effectiveness. (Predictive)

Q10: Monte Carlo and simulation methods are effective in determining business strategies. (Prescriptive)

Q11: Regression and trend analysis is important in determining business objectives. (Prescriptive)

Q12: Prescriptive techniques and analysis are used in the management of business processes. (Prescriptive)

Q13: Prescriptive optimization models contribute to the cost performance and control of the enterprise. (Prescriptive) 


\subsubsection{The Management Accounting}

To measure management accounting variables, the literature on management accounting practices was reviewed (Atkinson et al. 2011; Anderson and Lanen, 1999).

\subsubsection{The Cost Performance}

It is a 6-item scale specially prepared for this resear$c h$. The questions in the measurement tool are,

$\mathrm{CP} 1$. The cost structure of our business provides the advantage to compete with our competitors.

$\mathrm{CP} 2$. Our costs contribute to the profitability of our business.

CP3. Costs achieved are consistent with targeted costs.

CP4. Cost planning of our company is done successfully.

CP5. The expense behavior of our business shows a tendency to help us achieve our goals.

CP6. The efficiency of both direct and indirect costs is high.

\subsection{Analysis and Results}

First, we performed reliability and factor analysis. Secondly, hypothesis tests, intermediate variable analysis, and additional tests are performed. To determine the appropriateness of the sample to the normal distribution, the data set was evaluated for kurtosis and skewness values. Table 2 displays normality and descriptive results

Table 2: Normality, and Descriptive Statistics

\begin{tabular}{|l|l|l|l|l|}
\hline & Kurtosis & Skewness & Mean & $\begin{array}{l}\text { Standard } \\
\text { Deviation }\end{array}$ \\
\hline Cost performance & 1.22 & 0.81 & 3.77 & 0.39 \\
\hline Management & & & & \\
\hline Accounting & & & & \\
\hline P. Control & 1.51 & 0.73 & 3.48 & 0.25 \\
C. Management & 1.68 & 0.44 & 3.54 & 0.30 \\
P. M. Evaluation & 1.13 & 0.18 & 3.11 & 0.49 \\
\hline Business Analytics & & & & \\
Descriptive BA & -0.32 & -0.18 & 1.93 & 0.48 \\
Predictive BA & -0.49 & -0.23 & 1.84 & 0.61 \\
Prescriptive BA & -0.40 & -0.57 & 1.75 & 0.38 \\
\hline
\end{tabular}

The mean of cost performance variable was determined as $(\mu=3.77)$. Cost management stands out as the most important dimension of management accounting ( $\mu=3.68)$. Other variables were determined as ( $\mu=3.48$ and $\mu=3.11$ ) respectively. Highest mean value belongs to the descriptive dimension in business analytics ( $\mu=1.93$ ). The lowest values belong to prescriptive analytics. $(\mu=1.75)$. We performed the cluster analysis to test differentiation by sector type. Table 3 displays the cluster analysis findings.

We performed ANOVA and Cohen's $d$ factor analysis test the increase of representation power in determining the difference between means. Manufacturing has the highest values for Cost performance in the context

Table 3: Cluster Analysis by Industry

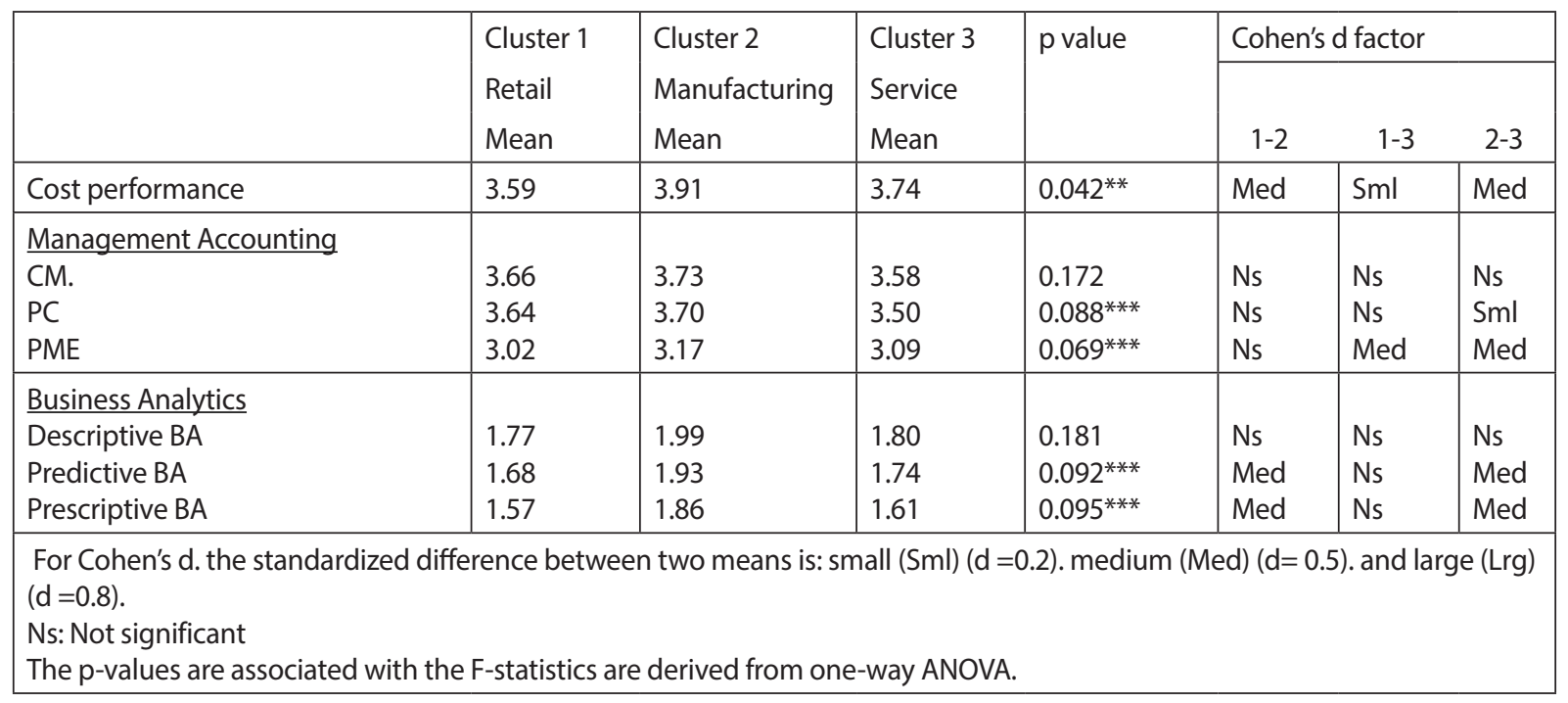

${ }^{*} \mathrm{p}<0.01 ;{ }^{* *} \mathrm{p}<0.05 ;{ }^{* * *} \mathrm{p}<0.10$. 
of industry averages $(\mu=3.91)$. Cost-effectiveness levels of service and retail businesses are close to each other (Cohen's d factor=Sml). The difference between production companies and other groups was found to be "Medium" ( $p=0.042)$. Highest value for cost management is seen in manufacturing companies $(\mu=3.73)$. Both F-test and Cohen's $d$ factor analysis showed that there was no significant difference between clusters $(p=0.0172)$. There is a significant difference between the means of clusters for performance measurement and evaluation ( $p=0.069$ ). However, according to Cohen's analysis, the difference is between manufacturing and service. There is no significant difference between retail and manufacturing enterprises. Retail is at a moderate level ( $\mu=3.52)$. According to Cohen's analysis, there is no significant difference between retail and service. However, the difference between retail, service, and manufacturing is at the "medium" level.

Descriptive analytics mean is highest in manufacturing enterprises $(\mu=1.99)$. There was no significant difference between sectors according to both F-test and Cohen's $d$ factor analysis ( $p=0.181$ ). For Predictive, the difference between clusters is significant ( $p=0.092)$. Cohen's analysis confirms the findings for comparisons (1-2) and (2-3). F-test results show that there is a significant difference in prescriptive context $(p=0.095)$. Similar results are found in Cohen's analysis. The difference between Retail and Manufacturing is "medium". Figure 2 reflects the statistical values of the sector means in terms of cost performance variable.

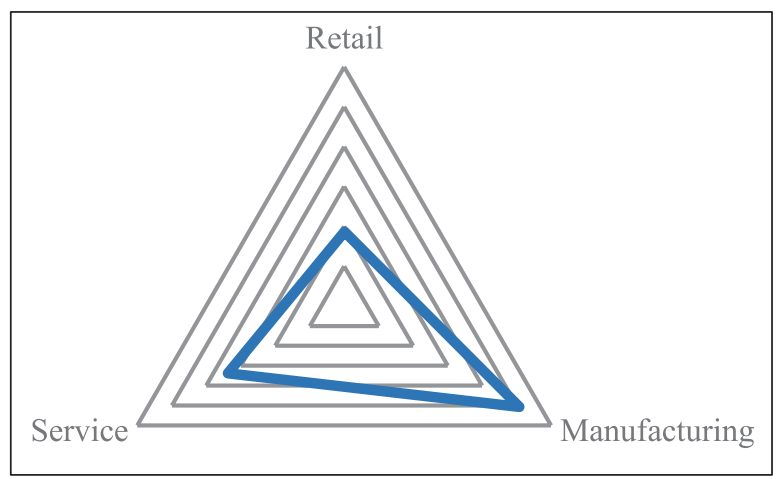

Figure 2: Cost performance Tendency by Industry

In terms of business analytics, sectoral orientations are described in Figure 3.
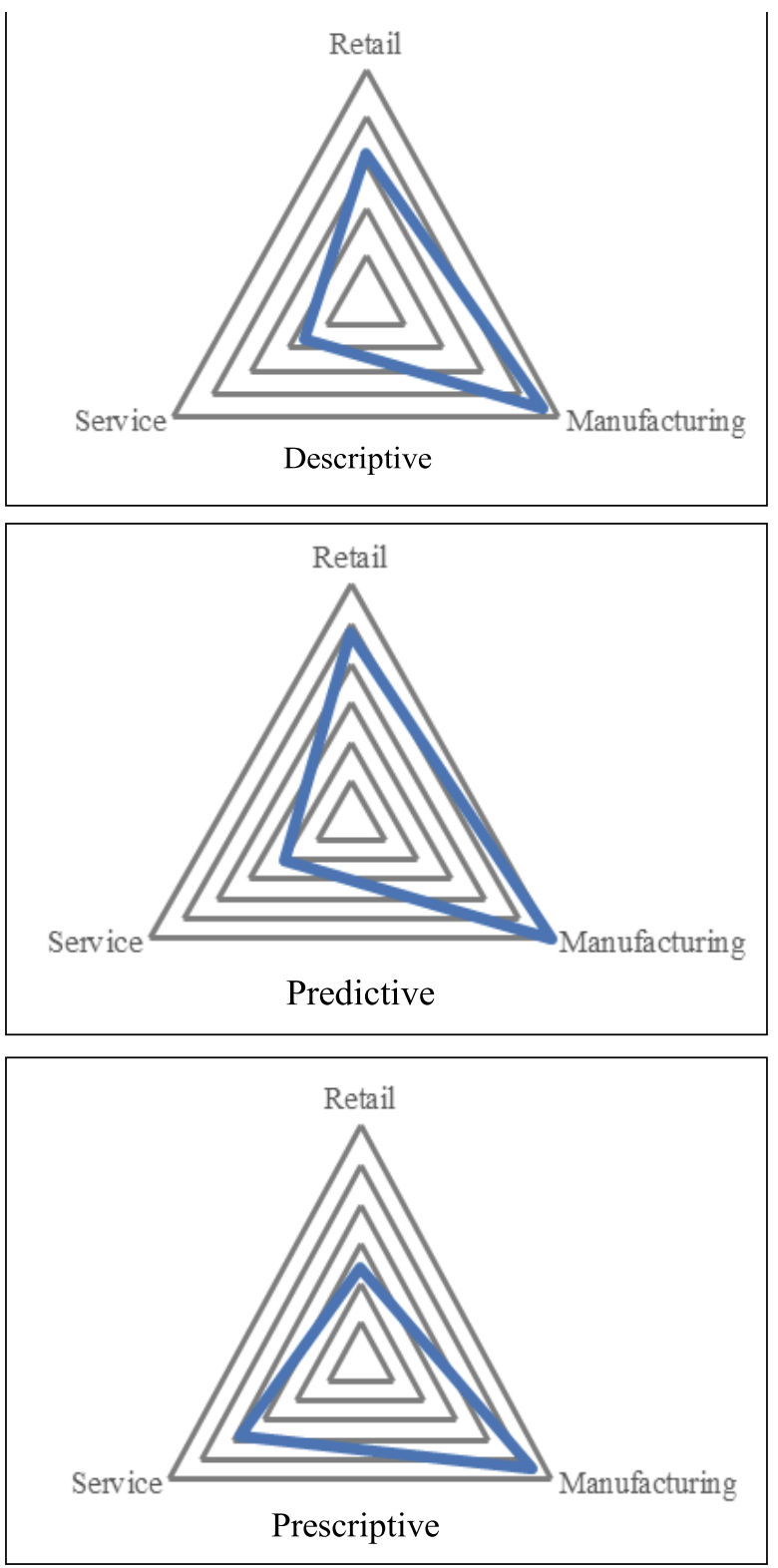

Figure 3: The tendency of Industry by Sub-

Dimensions of Business Analytics

Table 4 displays the reliability, KMO, and factor analysis results of the research variables.

$\mathrm{KMO}$ results show that there is significant factor structure for business analytics $(\mathrm{KMO}=0.821 ; \mathrm{KMO}=0.835$; $\mathrm{KMO}=0.812$ ). The results of factor analysis confirm that business analytics consists of three sub-dimensions as descriptive, predictive, and prescriptive as stated in the theoretical framework. The reliability values of the scales confirm that the questions are reliable for measurement. Factor analysis and reliability analysis were performed for cost performance and management accounting. Table 5 shows the findings. 
Table 4: Factor Analysis and Reliability for Business Analytics

\begin{tabular}{|l|l|}
\hline Descriptive BA (Cronbach's Alpha: $\mathbf{0 . 8 2 1}$ and KMO: $\mathbf{0 . 8 3 0}$ ) & Factor Loads \\
\hline Q1: In our company, ratio analysis, clustering models, process mining, Spearman rank correlations are used effectively. & 0.794 \\
\hline Q2: We frequently use descriptive statistics such as arithmetic mean, standard deviation, median about our activities. & 0.787 \\
\hline Q3: Statistical descriptors and ratio analysis are used in the control activities of our business. & 0.792 \\
\hline $\begin{array}{l}\text { Q4: Decision-making process in our enterprise is conducted comparing the data obtained from internal sources with } \\
\text { the data obtained from the external sources. }\end{array}$ & 0.780 \\
\hline Predictive BA (Cronbach's Alpha: $\mathbf{0 . 8 3 5}$ and KM0: 0.838) & 0.814 \\
\hline $\begin{array}{l}\text { Q5: Artificial neural networks, probability theory models, operations research, support vector machines are used } \\
\text { frequently by our company. }\end{array}$ & 0.799 \\
\hline Q6: Expert systems and decision tree methods are included in business processes by our company. & 0.801 \\
\hline Q7: In planning activities, analytical hierarchy processes method is used effectively. & 0.795 \\
\hline Q8: Predictive analysis and techniques are important for the management of our processing. & 0.806 \\
\hline Q9: Predictive analysis and techniques provide benefits for cost control and effectiveness. & 0.789 \\
\hline Prescriptive BA (Cronbach's Alpha: $\mathbf{0 . 8 1 2}$ and KMO:0.817) & 0.783 \\
\hline Q10: Monte Carlo and simulation methods are effective in determining business strategies. & 0.780 \\
\hline Q11: Regression and trend analysis is important in determining business objectives. & 0.782 \\
\hline Q12: Prescriptive techniques and analyzes are used in the management of business processes. & \\
\hline Q13: Prescriptive optimization models contribute to the cost performance and control of the enterprise. & \\
\hline
\end{tabular}

Table 5: Factor and Reliability Analyses for Cost-Performance and Management Accounting

\begin{tabular}{|c|c|}
\hline & Factor Loads \\
\hline \multicolumn{2}{|l|}{ (Cronbach's Alpha: 0.847 and KMO: 0.853) } \\
\hline The cost structure of our business provides the advantage to compete with our competitors. & 0.812 \\
\hline Our costs contribute to the profitability of our business. & 0.819 \\
\hline Costs achieved are consistent with targeted costs. & 0.830 \\
\hline Cost planning of our company is done successfully. & 0.827 \\
\hline The expense behavior of our business shows a tendency to help us achieve our goals. & 0.838 \\
\hline The efficiency of both direct and indirect costs is high. & 0.792 \\
\hline \multicolumn{2}{|l|}{ Managerial Accounting } \\
\hline (Cronbach's Alpha: 0.836 and KMO:0.844) & \\
\hline Flexible Budgeting & 0.822 \\
\hline Zero Based Budgeting & 0.804 \\
\hline Cash Budgeting & 0.791 \\
\hline Increased Budgeting & 0.794 \\
\hline Activity-Based Budgeting & 0.800 \\
\hline Balanced Score Card & 0.788 \\
\hline (Cronbach's Alpha: 0.841 and KMO:0.850) & \\
\hline Target Costing & 0.843 \\
\hline Product Life-cycle Costing & 0.840 \\
\hline Activity Based Costing & 0.832 \\
\hline Value Chain Analysis & 0.859 \\
\hline Traditional Cost Techniques & 0.825 \\
\hline Performance Measurement and Evaluation & \\
\hline Customer Profit Analysis & 0.790 \\
\hline Data Envelopment Analysis & 0.777 \\
\hline Department Productivity Analysis & 0.782 \\
\hline Ratio Analysis & 0.829 \\
\hline Product Profitability Analysis & 0.801 \\
\hline Profitability Analysis & 0.772 \\
\hline Operations Analysis & 0.757 \\
\hline Shareholder Value Analysis & 0.820 \\
\hline Sales Analysis & 0.703 \\
\hline Breakeven Point Analysis & 0.818 \\
\hline
\end{tabular}


Reliability and KMO values confirm the suitability of the findings for further analysis. The question items of the cost performance variable were found to be reliable. $(a=0.847)$. KMO value is significant $(0.844)$. Table 6 shows the correlations and the validity values of construct variables.

It is understood from the parameters in Table 6 that the variables have significant values in terms of validity. Validity is significant for descriptive analytics $(\sqrt{ } A V E=0.826)$. The validity parameters of the predictive and prescriptive factors also indicate a very high level $(\sqrt{ } A V E=0.819$ and $\sqrt{ } A V E=0.805)$. The findings confirm that the structures constituting the business analytics factor are valid. The validity score of the cost management factor indicates a significant level $(\sqrt{ } \mathrm{AVE}=0.836)$.
Performance measurement and evaluation have construct validity ( $\sqrt{ } \mathrm{AVE}=0.802)$. Cost performance has been validated as a construct $(\sqrt{ } A V E=0.894)$. Correlation values between variables reveal the presence of medium and low-level positive linear relations.

We tested the hypotheses after validity and correlation analysis. Hypotheses were tested using regression analysis. We performed multi-linear regression to measure the joint effect.The research model has been tested in two stages. First, the relationship between business analytics and management accounting was analyzed. Second, the impact of business analytics and management accounting on cost performance was tested. Estimation value $\left(Q^{2}\right)$ and effect size $\left(f^{2}\right)$ values were also included in the analysis.

Table 6: Correlation coefficient matrix and discriminant validity

\begin{tabular}{|l|l|l|l|l|l|l|l|}
\hline & $\sqrt{ }$ AVE & DES BA & PRE BA & PRS BA & COSM & PLAC & PEMA \\
\hline DES BA & 0.826 & & & & & & \\
\hline PRE BA & 0.819 & $0.367^{* *}$ & & & & & \\
\hline PRS BA & 0.805 & $0.354^{* *}$ & $0.416^{*}$ & & & & \\
\hline COSM & 0.836 & $0.188^{* * *}$ & $0.195^{* * *}$ & $0.228^{* * *}$ & & & \\
\hline PLAC & 0.845 & 0.103 & $0.178^{* * *}$ & $0.204^{* * *}$ & $0.250^{* * *}$ & & \\
\hline PEMA & 0.802 & 0.056 & 0.063 & 0.089 & $0.202^{* * *}$ & $0.165^{* * *}$ & \\
\hline COPR & 0.894 & $0.314^{* *}$ & $0.269^{* * *}$ & $0.232^{* * *}$ & $0.366^{* *}$ & $0.339^{* *}$ & $0.274^{* * *}$ \\
\hline
\end{tabular}

DES BA: Descriptive Business Analytics; PRE BA: Predictive Business Analytics; PRS BA: Prescriptive Business Analytics; COSM: Cost Management; PLAC: Planning and Control; PEMA: Performance Measurement and Evaluation; COPR: Cost Performance; AVE: Average Variance Extracted.

Italic Values refer to Correlation Coefficients.

${ }^{*} \mathrm{p}<0.01 ;{ }^{* *} \mathrm{p}<0.05 ;{ }^{* * *} \mathrm{p}<0.10$.

Table 7: Association Between Business Analytics and Management Accounting

\begin{tabular}{|c|c|c|c|c|c|c|}
\hline & \multicolumn{6}{|c|}{ Cost Management } \\
\hline Construct & $\beta$ & $\varepsilon$ & $R^{2}$ & $Q^{2}$ & $f^{2}$ & Decision \\
\hline Descriptive BA & $0.17^{* * *}$ & 0.053 & 0.128 & 0.179 & 0.144 & H1a: Supported \\
\hline Predictive BA & $0.21^{* *}$ & 0.039 & 0.204 & 0.180 & 0.173 & H1b: Supported \\
\hline \multirow[t]{3}{*}{ Prescriptive BA } & $0.26^{* *}$ & 0.028 & 0.229 & 0.185 & 0.179 & H1c: Supported \\
\hline & \multicolumn{6}{|c|}{ Planning and Control } \\
\hline & $\beta$ & $\varepsilon$ & $R^{2}$ & $Q^{2}$ & $f^{2}$ & Decision \\
\hline Descriptive BA & 0.04 & 0.142 & 0.033 & 0.080 & 0.088 & H1d: Not Supported \\
\hline Predictive BA & $0.16^{* * *}$ & 0.075 & 0.119 & 0.172 & 0.145 & H1e: Supported \\
\hline \multirow[t]{3}{*}{ Prescriptive BA } & $0.22^{* *}$ & 0.037 & 0.207 & 0.180 & 0.178 & H1f: Supported \\
\hline & \multicolumn{6}{|c|}{ Performance Measurement and Evaluation } \\
\hline & $\beta$ & $\varepsilon$ & $R^{2}$ & $Q^{2}$ & $f^{2}$ & Decision \\
\hline Descriptive BA & 0.02 & 0.153 & 0.016 & 0.054 & 0.053 & H1g: Not Supported \\
\hline Predictive BA & 0.11 & 0.099 & 0.057 & 0.072 & 0.069 & H1h: Not Supported \\
\hline Prescriptive BA & $0.15^{* * *}$ & 0.081 & 0.104 & 0.160 & 0.143 & H1i: Supported \\
\hline
\end{tabular}

${ }^{*} \mathrm{p}<0.01 ;{ }^{* *} \mathrm{p}<0.05 ;{ }^{* * *} \mathrm{p}<0.10$. 
Descriptive business analytics applications have a significant and positive effect on cost management ( $\beta=0.17$ and $R^{2}=0.128$ ). The use of descriptive methods and approaches contributes to the business focusing more on cost-effectiveness. Based on the findings, "H1a: The more intensive use of descriptive business analytics by the enterprise positively affects the cost management dimension of management accounting" was confirmed. Descriptive data strengthens the company's control over cost components and cost-effectiveness. The spread of descriptive statistical methods and tools facilitates the decision-making of the enterprise. Estimation of the relevant hypothesis shows that it is significant $\left(Q^{2}=0.179\right)$. The effect size for descriptive business analytics is moderate $\left({ }^{2}=0.144\right)$. In other words, descriptive analytics show a moderate impact on cost management. The effect of predictive business analytics variable on cost management was significant and positive $\left(\beta=0.21\right.$ and $\left.R^{2}=0.204\right)$. Predictive analytics is a factor that improves both cost and noncost performance of firms. " $\mathrm{H} 1 \mathrm{~b}$ : The more intensive use of predictive business analytics by the enterprise positively affects cost management function" was supported. Predictive analysis techniques contribute to better risk management. The estimation power of the hypothesis was determined to be significant and significant $\left(Q^{2}=0.180\right)$. Predictive business analytics have a high impact on cost management $\left(f^{2}=0.173\right)$. Cost management is highly influenced by the predictive business analytics variable.

The relationship between the prescriptive dimension of business analytics and cost management is evaluated in the hypothesis " $\mathrm{H} 1 \mathrm{c}$ : The more intensive use of business analytics by the enterprise is positively associated with the cost management". Prescriptive business analytics has a significant impact on the cost management ( $\beta=0.26$ and $R^{2}=0.229$ ). More intensive use of prescriptive techniques and approaches impro- ves cost management positively. Prescriptive business analytics improves the quantitative aspect of firm performance, particularly by providing risk control. It contributes by developing suggestions for a prescriptive analytics solution to ensure the compliance of cost structure with business objectives. Value of hypothesis estimation is significant $\left(Q^{2}=0.185\right)$. The size of the effect is statistically significant $\left(f^{2}=0.179\right)$.

When the relations between business analytics components and planning and control are examined, the findings are as follows. The relationship between descriptive business analytics and planning and control is not significant. The coefficient of the related regression equation is not significant $\left(\beta=0.04\right.$ and $R^{2}=0.033$ ). The degree of relevance of the hypothesis is not significant $\left(Q^{2}=0.080\right)$. Impact size is low $\left(P^{2}=0.088\right)$. Predictive business analytics have a positive impact on planning and control ( $\beta=0.16$ and $R^{2}=0.119$ ). ${ }^{\prime} \mathrm{H} 1 \mathrm{e}$ : The predictive business analytics positively affects the planning and control activities in the enterprises" was supported. The effect size of the hypothesis is relatively low but significant $\left(f^{2}=0.172\right)$. The estimation power between variables was determined as appropriate $\left(Q^{2}=0.145\right)$. Prescriptive business analytics have a significant impact on planning and control $\left(\beta=0.22\right.$ and $\left.\mathrm{R}^{2}=0.209\right)$. " $\mathrm{H} 1 \mathrm{f}$ : The prescriptive business analytics positively affects the planning and control activities in the enterprises" was accepted the degree of the effect size of the hypothesis was found to be moderate. $\left(f^{2}=0.178\right)$. The estimated value of the hypothesis is also moderate $\left(Q^{2}=0.180\right)$.

Descriptive business analytics do not have a significant impact on performance measurement and evaluation ( $\beta=0.02$ and $R^{2}=0.016$ ). ${ }^{\prime} \mathrm{H} 1 \mathrm{~g}$ : The descriptive business analytics positively affects the performance measurement and evaluation in the enterprises" was not supported. Predictive business analytics do not significantly affect performance measurement and

Table 8: Direct and Joint Effects on Cost performance

\begin{tabular}{|l|l|l|l|l|l|l|}
\hline & $\beta$ & $\varepsilon$ & $R^{2}$ & $\mathrm{Q}^{2}$ & $f^{2}$ & Decision \\
\hline Descriptive BA & $0.22^{* *}$ & 0.043 & 0.200 & 0.166 & 0.185 & H2a: Supported \\
\hline Predictive BA & $0.17^{* * *}$ & 0.059 & 0.154 & 0.150 & 0.181 & H2b: Supported \\
\hline Prescriptive BA & $0.15^{* * *}$ & 0.068 & 0.139 & 0.148 & 0.178 & H2c: Supported \\
\hline Cost Management & $0.30^{*}$ & 0.020 & 0.236 & 0.203 & 0.210 & H3a: Supported \\
\hline Planning and Control & $0.27^{* *}$ & 0.026 & 0.213 & 0.194 & 0.198 & H3b: Supported \\
\hline Performance Measurement and Evaluation & $0.19^{* *}$ & 0.049 & 0.161 & 0.152 & 0.145 & H3c: Supported \\
\hline Business analytics X Management Accounting & $0.48^{*}$ & 0.014 & 0.603 & 0.230 & 0.249 & H4: Supported \\
\hline
\end{tabular}

${ }^{*} \mathrm{p}<0.01 ;{ }^{* *} \mathrm{p}<0.05 ;{ }^{* * *} \mathrm{p}<0.10$ 
evaluation ( $\beta=0.11$ and $\mathrm{R}^{2}=0.057$ ). ${ }^{\mathrm{H}} \mathrm{H} 1 \mathrm{~h}$ : The predictive business analytics is positively associated with the performance measurement and evaluation in the enterprises" was not supported. The relevant indicators confirm that predictive analytics does not have a significant and powerful effect on measurement and evaluation $\left(Q^{2}=0.072\right.$ and $\left.f^{2}=0.069\right)$. Prescriptive analytics affects performance measurement and evaluation $(\beta=0.15$ and $\left.R^{2}=0.104\right)$. " $H 1$ i: The prescriptive business analytics affects the performance measurement and evaluation activities in the enterprises in the positive direction" was supported. The impact size is medium according to the finding $\left(f^{2}=0.143\right.$ and $\left.Q^{2}=0.160\right)$. Table 8 shows the independent and joint impact of both business analytics and management accounting on cost performance. We performed multi-linear regression to measure the joint effect.

Descriptive business analytics has a significant effect on cost performance $\left(\beta=0.22\right.$ and $R^{2}=0.200$ ). The use of descriptive methods and approaches contributes to a greater focus on cost performance. Based on the findings, "H2a: The descriptive business analytics positively
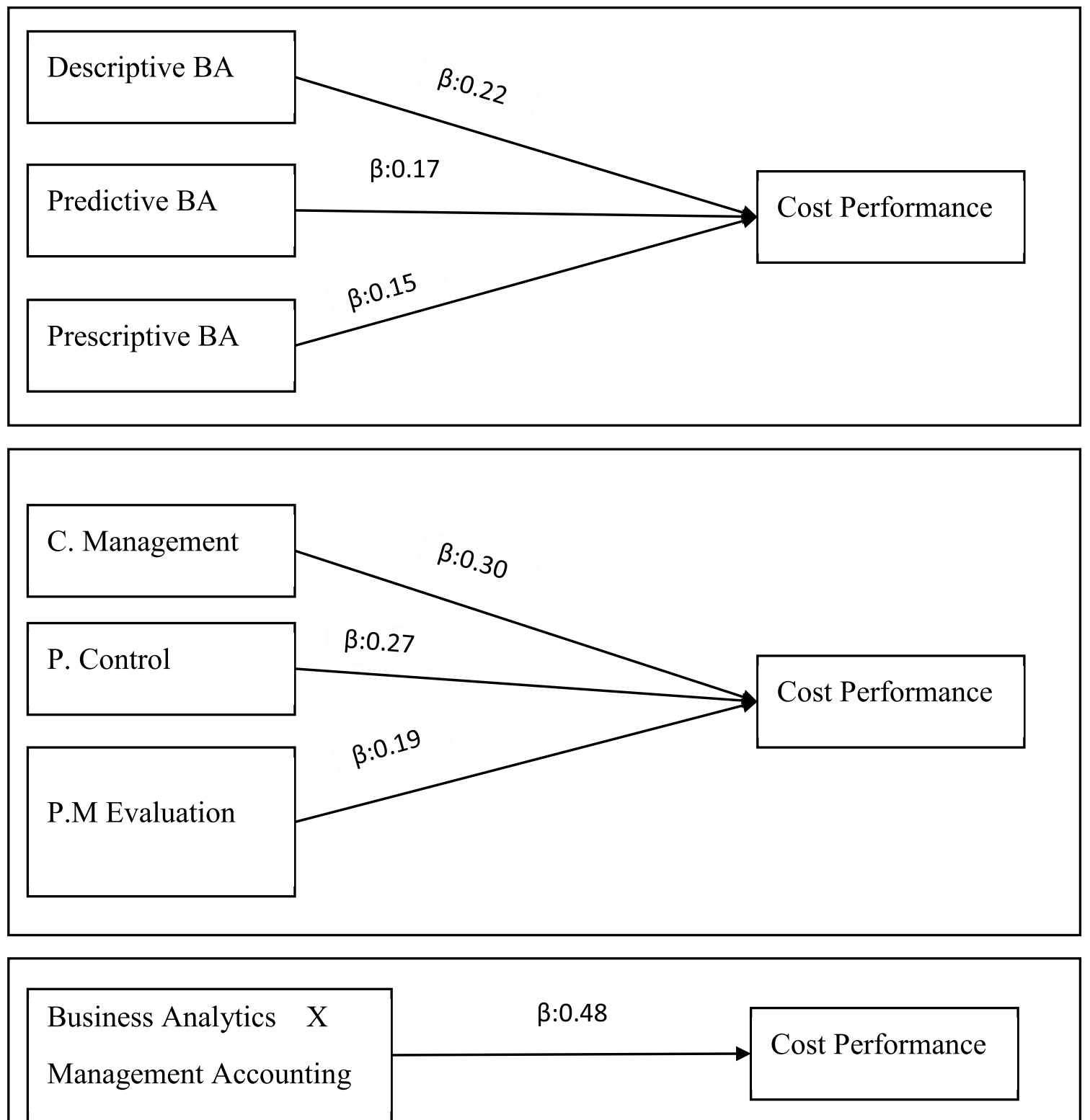

Figure 4: Direct and Joint Effects on Cost Performance 
affects the cost performance" was accepted. Descriptive analytics strengthens the company's control over cost components and cost success. Cost-related risk analytics give positive results in the firm's control efforts. The widespread use of descriptive statistical methods and tools paves the way for rapid decision-making on cost performance. Decisions resulting from descriptive analytics improve cost performance. The estimation ability of the hypothesis shows that it is significant $\left(Q^{2}=0.166\right)$. The effect size for descriptive business analytics is moderate $\left(f^{2}=0.185\right)$. Predictive analytics effect on cost performance is significant $\left(\beta=0.17\right.$ and $\left.R^{2}=0.154\right)$. Predictive analytics is a factor that improves both cost and non-cost performance of firms. In this context, " $\mathrm{H} 2 \mathrm{~b}$ : The predictive business analytics positively affects cost performance" was accepted. Estimation-based analysis techniques contribute to better cost determination of firms. The predictability of the hypothesis was determined to be significant $\left(Q^{2}=0.150\right)$. Predictive business analytics have a high-level impact on cost performance $\left(f^{2}=0.181\right)$.

The relationship between prescriptive analytics and cost performance is tested in the hypothesis " $\mathrm{H} 2 \mathrm{c}$ : The prescriptive business analytics is positively associated with the cost performance". Results show that the prescriptive analytics has a significant impact on cost performance $\left(\beta=0.15\right.$ and $\left.R^{2}=0.139\right)$. The more intensive use of prescriptive techniques and approaches brings into the better the cost performance. Prescriptive analytics develops quantitative-qualitative aspects of organizational performance. Degree of hypothesis estimation is significant $\left(Q^{2}=0.148\right)$. The size of the effect is statistically significant $\left(f^{2}=0.178\right)$.

The association between cost management and cost performance is positive and significant. The coefficient of the related regression equation is high $(\beta=0.30$ and $R^{2}=0.226$ ). " $H 3$ a: The cost management dimension of the management accounting positively affects the cost performance in the enterprises" was accepted. The effect size and prediction power of the relationship are significant $\left({ }^{2}=0.197\right.$ and $\left.Q^{2}=0.203\right)$. Planning and control have a positive impact on cost performance $\left(\beta=0.27\right.$ and $\left.R^{2}=0.213\right)$. The effect size of the relationship in the hypothesis is relatively high and significant $\left(f^{2}=0.194\right.$ and $\left.Q^{2}=0.198\right)$. The findings support $\mathrm{H} 3 \mathrm{C}$ $\left(\beta=0.19\right.$ and $\left.R^{2}=0.161\right)$. The effect and adequacy level of the hypothesis was found to be moderate $\left(P^{2}=0.145\right.$ and $Q^{2}=0.152$ ). The joint impact of business analytics and management accounting on cost performance is positive and significant ( $\beta=0.48$ and $R^{2}=0.603$ ). " $H 4$ : The business analytics and management accounting affect the cost performance of enterprises positively" was confirmed. Both estimation ability and effect size of the relationship is at high-level $\left(Q^{2}=0.230\right.$ and $\left.P^{2}=0.249\right)$. In this context, management accounting and business analytics significantly affect the cost performance of enterprises. Figure 4 shows the direct and indirect effects of independent variables on cost performance.

The distribution of regression coefficients by sectors is important for understanding the details of the research model. Table 9 shows the joint impact of business analytics and management accounting variables on cost performance by sector.

The interaction cost between business analytics and management accounting affects performance in most manufacturing companies $(\beta=0.55)$. Business analytics and management accounting cost can have a high impact on performance, as intensive cost analysis and evaluation is carried out in manufacturing enterprises. The regression coefficient for retail was significant and high ( $\beta=0.43$ ). Management accounting applications and business analytics techniques affect the decision-making processes and cost management of retail companies. The regression coefficient of service companies is lower than in other industries $(\beta=0.40)$. The interaction between business analytics, management accounting and, organization size has been found to have a high impact on cost performance for manufacturing firms $(\beta=0.59)$. The interaction effect of independent variables is also very high in the retail industry ( $\beta=0.50$ and $\left.R^{2}=0.574\right)$. The impact is signifi-

Table 9: Joint Effects on Cost performance by Industry

\begin{tabular}{|l|l|l|l|l|l|l|}
\hline & \multicolumn{2}{l|}{ Retail } & \multicolumn{2}{l|}{ Manufacturing } & \multicolumn{2}{l|}{ Service } \\
\hline Construct & $\beta$ & $R^{2}$ & $\beta$ & $R_{2}$ & $\beta$ & $R^{2}$ \\
\hline Business analytics X Managerial Accounting & $0.43^{*}$ & 0.474 & $0.55^{*}$ & 0.628 & $0.40^{*}$ & 0.419 \\
\hline $\begin{array}{l}\text { Business analytics X Managerial Accounting X } \\
\text { Organization Size (Control Variable) }\end{array}$ & $0.50^{*}$ & 0.574 & $0.59^{*}$ & 0.637 & $0.44^{*}$ & 0.480 \\
\hline
\end{tabular}

${ }^{*} \mathrm{p}<0.01 ;{ }^{* *} \mathrm{p}<0.05 ;{ }^{* * *} \mathrm{p}<0.10$ 
cant and positive for service companies $(\beta=0.44$ and $R^{2}=0.480$ ).

Determining indirect effects is an important contribution to the study. For this purpose, mediation analysis was performed to determine the role of management accounting in the relationship between business analytics and cost performance. MacKinnon (1994) states that four conditions must be met for mediation analysis: (i) There should be a significant relationship between independent variables and dependent variables. (ii) Independent variable (Business analytics) should be significantly related to the hypothesized mediator (management accounting). (iii) The mediator variable should have more effect on the dependent variable than the independent variable. (iv). The mediating effect should be statistically significant. In this study, a single mediator model approach was adopted and " $\mathrm{H5}$ : There is a significant indirect relationship between business analytics and cost performance through the use of management accounting system" was tested. Table 10 reflects the mediator role of management accounting in the relationship between business analytics and cost performance.

Table 10: Sobel Test for The Mediator Role of Management Accounting

\begin{tabular}{|l|l|l|l|}
\hline & $Z$ & Standard Error & $p$ \\
\hline Sobel Test & 2.402 & 0.029 & $0.037^{* *}$ \\
\hline
\end{tabular}

${ }^{*} p<0.01 ;{ }^{* *} p<0.05 ;{ }^{* * *} p<0.10$

According to the results of mediation analysis, the indirect effect of business analytics factor on cost performance was significant. According to Sobel test results, management accounting is a mediator variable that increases or decreases the degree of impact of business analytics factor on cost performance $(Z=2.402$ and $\mathrm{p}=0.037$ ). In this context, the more adapted companies in management accounting, the higher the effectiveness of business analytics. "H5: There is a significant indirect relationship between business analytics to cost performance through the use of management accounting system" was supported.

Table 11 shows a multivariate analysis of variance (MANOVA) explaining the extent to which factors varied among the participants. Demographic characteristics [gender, age, experience, job title] and factors [business analytics, management accounting system] were evaluated in [4×2] dimension.
Table 11: Results of MANOVA for Demographics of Participants.

\begin{tabular}{|l|l|l|}
\hline & Business Analytics & $\begin{array}{l}\text { Management } \\
\text { Accounting System }\end{array}$ \\
\hline & Multivariate F Value & Multivariate F Value \\
\hline Gender & $7.78^{* *}$ & $3.44^{* * *}$ \\
\hline Age & 2.07 & 1.39 \\
\hline Experience & $3.20^{* * *}$ & 0.90 \\
\hline Job Title & 1.11 & 0.72 \\
\hline
\end{tabular}

Multivariate analysis results displays business analytics value differ significantly in terms of gender $(F=7.78)$. Evaluations of the management accounting system factor vary according to the gender variable $(F=3.44)$. Evaluations for business analytics and management accounting do not differ significantly in terms of age category ( $F=2.07$ and $F=1.39$ ). Participants respond for business analytics vary in experience category $(F=3.20)$. However, the experience is not a distinguishing factor for management accounting ( $\mathrm{F}=0.90)$. There is no significant difference in terms of the job title for business analytics and management accounting system ( $F=1.11$ and $\mathrm{F}=0.72$ ).

\section{Conclusion}

Advancement in science and technology is changing the classic data ecosystem of management accounting from inside of the organization to outside. Internet-centric change provides more ability to access, store and use more data and data types for management accounting. For the change in the amount and structure of the data to be positive, the management accounting system must understand and use the business analytics correctly. The increase in the efficiency of the management accounting system will positively affect organizational cost performance. Activities such as cost reduction, analysis of cost structure, supplier selection, determination of cost behavior, determination of cost components that do not add value can be performed more efficiently through business analytics. The results of the research performed to test the structural relationships between business analytics, management accounting, and cost performance are as follows,

Descriptive business analytics provides the statistical and visual data required for cost management effectively. In addition, the raw data required for performing descriptive statistics and regression analysis is produced by descriptive analytics, making it easier for 
accounting to perform its planning and control functions. Descriptive analytics reduce the firm's dependence on financial statements, sales reports, and internal documentation in measuring past performance. In this way, the performance measurement and evaluation effectiveness of accounting are improved.

Predictive business analytics includes analytical and multidimensional analysis such as regression, mathematical modeling, decision tree and scenario, game theory, probability modeling instead of traditional and financial weighted applications such as ratio analysis, comparative table analysis, percentage analysis, profitability analysis. Thus, accounting management can evaluate many qualitative and quantitative variables and indicators besides financial analysis. Determining customer expectations and behaviors becomes easier for the enterprise owing to predictive models. Thus, the phenomenon of change on the internet and real life is reflected in the firm's forecasts. Predictive analysis also enables greater involvement of the political, economic, and social environment in the firm's plans. It may be possible to develop targets and develop strategies by comparing the findings of the performance measurement performed by management accounting and the findings provided by predictive analytics by using both together.

Prescriptive analytics prevents the firm from seeing accounting as a necessity. By using analytics, the accounting influences strategy development, decision making and sustainability of the organization through prescriptive techniques. In addition, cost management, planning, and performance measurement can be performed more efficiently owing to prescriptive analytics. The findings displayed those analytical applications improve the cost performance of the firm. In this context, enterprises need to use analytics more in cost control and reduction. Management accounting has a mediator effect between business analytics and cost performance. In this context, business analytics must be integrated into accounting information system to affect performance.

Based on these implementation, it can be stated that businesses should move from a traditional accounting structure to a more comprehensive accounting system that has integrated analytics. The implementation and integration of analytics bring a challenging process for businesses and individuals. The staff needs to adapt to analytics and allocate more resources to the process management of enterprises for their implementation. As can be understood from the research findings, business analytics does not have the same effect in every sector. In this context, integration should be realized in the enterprises considering the sectoral differences. In this study, the effects of analytics on accounting and cost performance were evaluated in a limited sample. In future research, the relationship between risk analytics, business intelligence, and accounting analytics should be evaluated. In addition, the integration of analytics in institutional architecture should be explored. 


\section{REFERENCES}

Aydıner, A.S., Tatoğlu, E., Bayraktar, E., Zaim,S., \&Delen, D. (2019). Business analytics and firm performance: The mediating role of business process performance. Journal of Business Research, 96, 228-237.

Anderson, S.W. \& Lanen, W.N. (1999). Economic transition strategy and the evolution of management accounting practices: The case of India. Accounting, Organizations and Society, 24 (5-6), 379-412.

Anderson, S.W., \& Dekker, H.C. (2009). Strategic Cost Management in Supply Chains, Part 2: Executional Cost Management. Accounting Horizons, 29(3), 293-305.

Anderson, S.W., \& Lanen.,W.N. (2002). Using electronic data interchange (EDI) to improve the efficiency of accounting transactions. Accounting Review, 77(4),703-729.

Appelbaum, D., Kogan,A., Vasarhelyi, M., \& Yan, Z. (2017). Impact of business analytics and enterprise systems on managerial accounting. International Journal of Accounting Information Systems, 25,29-44

Atkinson, A. A., Kaplan, R.S., Matsumura, E.M. \& Young, S.M. (2011). Management Accounting: Information for Decision Making and Strategy Execution. 6 Pearson Education.

Basu, A. (2013). Five pillars of prescriptive analytics success. Analytics Magazine, 8-12.

Baştürk, S. \& Taştepe, M. (2013). Evren ve ömeklem. S. Baştürk (Ed.), Bilimsel Araştırma Yöntemleri (129- 159). Ankara: Vize Yayıncılık.

Brands, K. (2015). Business Analytics: Transforming the Role of Management Accountants. Management Accounting Quarterly, 16(3), 1-12.

Cadez,S.\&, Guilding, C. (2008). An exploratory investigation of an integrated contingency model of strategic management accounting. Accounting, Organizations and Society, 33(7-8), 836-863.

Chae, B.K., Yang, C., Olson, D., \& Sheu, C. (2014). The impact of advanced analytics and data accuracy on operational performance: a contingent resource based theory (RBT) perspective. Decision Support Systems, 59, 119-126.

Chen, I.J., \& Paulraj, A. (2004). Towards a theory of supply chain management: the constructs and measurements. Journal of Operations Management, 22, 119-150.

Cokins, G. (2013). Top 7 trends in management accounting. Strategic Finance. 95(6), 21-30.

Cooper, R., \& Slagmulder, R. (2004). Interorganizational cost management and relational context. Accounting, Organizations and Society, 29(1), 1-26.

Daniel, W.W., \& Cross, C.L. (2018). Biostatistics: A Foundation for Analysis in the Health Sciences, 11th Ed., Wiley.

Davenport, T. \& Harris, J.G. (2007). Competing on Analytics: The New Science of Winning. Harvard Business School Press, Boston, MA.
Davenport, T. (2006). Competing on analytics, Harvard Business Review, 84(5), 150-151.

Dilla, W., Janvrin, D.J., \& Raschke, R. (2010). Interactive data visualization: new directions for accounting information systems research. Journal of Information Systems, 24(2), 1-37.

Esfahbodi,A., Zhang, Y., \&Watson, G. (2016). Sustainable supply chain management in emerging economies: Trade-offs between environmental and cost performance. International Journal of Production Economics, 181, 350-366.

George, G. , Haas, M. , \& Pentland, A. (2014). Big data and management. Academy of Management Journal, 57(2), 321-326.

Granlund M. (2011). Extending AIS research to management accounting and control issues: A research note. International Journal of Accounting Information Systems, 12(1), 3-19.

Hedgebeth, D. (2007). Data-driven decision making for the enterprise: an overview of business intelligence applications, VINE, 37(4), 414-420.

Hindle, G. A., \& Vidgen, R. (2018). Developing a business analytics methodology: A case study in the foodbank sector. European Journal of Operational Research, 268(3), 836-851.

Holsapple, C., Lee-Post, A., \& Pakath, R. (2014). A unified foundation for business analytics. Decision Support Systems, 64, 130-141.

https://data.tuik.gov.tr/Bulten/Index?p=Kucuk-ve-Orta-Buyuklukteki-Girisim-Istatistikleri-2019-37548 (access date: 5 May, 2020).

IBM. (2013). Descriptive, predictive, prescriptive: transforming asset and facilities management with analytics. In:Thought Leadership White Paper.

Jans, M., Alles, M., \& Vasarhelyi, M. (2013). The case for process mining in auditing: Sources of value added and areas of application. International Journal of Accounting Information Systems , 14, 1-20.

Klatt, T., Schlaefke,M., \& Moeller, K. (2011). Integrating business analytics into strategic planning for better performance. Journal of Business Strategy, 32(6), 30-39.

Krishnamoorthi, S.,\& Mathew, S.K. (2018). Business analytics and business value: A comparative case study. Information \&Management, 55, 643-666.

Larson, D., \& Chang, V. (2016). A review and future direction of agile, business intelligence, analytics and data science. International Journal of Information Management, 36(5), 700-710.

MacKinnon, D.P. (1994). Analysis of mediating variables in prevention and intervention research, in Cazares, $A$. and Beatty, L.A. (Eds), Scientific Methods in Prevention Research, NIDA Research Monograph, Vol. 139, Government Printing Office, Washington, DC, pp. 127-153.

Maiga, A., \& Jacobs, F.A. (2003). Balanced Scorecard, Activity-based Costing and Company Performance: An Empirical Analysis. Journal of Managerial Issues, 15(3), 283-301. 
Maiga, A.S., Nilsson, A., \& Ax, C. (2015). Relationships between internal and external information systems integration, cost and quality performance, and firm profitability. International Journal of Production Economics, 169, 422-434.

Nielsen, S. (2015). The Impact of Business Analytics on Management Accounting. (Available at SSRN 2616363).

Pape, T. (2016). Prioritising data items for business analytics: Framework and ap- plication to human resources. European Journal of Operational Research, 252, 687-698.

Redman, T.C. (2013). Data Driven: Profiting From Your Most Important Business Asset. Harvard Business Press.

Scapens, R.W., \& Jazayeri, M. (2003). ERP systems and management accounting change: opportunities or impacts? A research note. European Accounting Review, 12(1), 201-233.

Shmueli, G., \& Koppius, O. R. (2011). Predictive Analytics in Information Systems Research. MIS Quarterly, 35(3), 553-572.

Silvi, R., Moeller, K., \& Schlaefke, M. (2010). Performance management analytics - the next extension in managerial accounting. available at: SSRN eLibrary, SSRN, doi: 10.2139/ ssrn. 1656486

Sivarajah, U., Kamal, M. M., Irani, Z., \& Weerakkody, V. (2017). Critical analysis of big data challenges and analytical methods. Journal of Business Research, 70, 263-286.

Stenzel,J., \&Stenzel.,C. (2004). Performance measurement and management in the reinsurance industry. Cost Management, 18(3), 28-35.
Sun, Z., Strang, K., \& Firmin, S. (2017). Business analytics-based enterprise information systems. The Journal of Computer Information Systems, 57(2), 169-178

Taleizadeh, A.A., Noori-daryan, M., \& Cárdenas-Barrón, L.E., (2015). Joint optimization of price, replenishment frequency, replenishment cycle and production rate in vendor managed inventory system with deteriorating items. International Journal of Production Economics, 159, 285-295.

Troilo, M., Bouchet, A., Urban, T. L., \& Sutton, W. A. (2016). Perception, reality, and the adoption of business analytics: Evidence from North American professional sport organizations. Omega, 59, 72-83.

Vidgen, R., Shaw, S., \& Grant, D.B. (2017). Management challenges in creating value from business analytics, European Journal of Operational Research, 261, 626-639.

Warren Jr., J.D., Moffitt, K.C., \& Byrnes, P. (2015). How big data will change accounting. Accounting Horizons, 29(2), $397-$ 407.

Wong,C.Y., Boon-itt,S.,\& Wong.,C.W.Y. (2011). The contingency effects of environmental uncertainty on the relationship between supply chain integration and operational performance. Journal of Operation Management, 29, 604-615.

Wonnacott, T.H. \& Wonnacott, R.J. (1990). Introductory Statistics, $5^{\text {th }}$ Ed. Wiley.

Zikopoulos, P. , Eaton, C. , DeRoos, D. , Deutsch, T. , \& Lapis, G. (2012). Understanding big data: Analytics for enterprise class hadoop and streaming data. Maidenhead, UK: McGraw-Hill. 